\title{
Effect of Aging and Sex on Circulating MicroRNAs in Humans
}

\author{
Shuji Sawada1*, Takayuki Akimoto², Masaki Takahashi3, Ryota Sakurai ${ }^{4}$, Shoji Shinkai, \\ Takashi Ushida' ${ }^{2}$, Yoshinori Fujiwara ${ }^{4}$, Katsuhiko Suzuki ${ }^{1,3}$ \\ ${ }^{1}$ Institute for Nanoscience \& Nanotechnology, Waseda University, Wakamatsu-cho 2-2, Shinjuku-ku, \\ Tokyo, Japan \\ ${ }^{2}$ Division of Regenerative Medical Engineering, Center for Disease Biology and Integrative Medicine, Graduate \\ School of Medicine, The University of Tokyo, 7-3-1 Hongo, Bunkyo, Tokyo, Japan \\ ${ }^{3}$ Faculty of Sports Science, Waseda University, Mikajima 2-579-15, Tokorozawa, Saitama, Japan \\ ${ }^{4}$ Research Team for Social Participation and Community Health, Tokyo Metropolitan Institute of Gerontology, \\ 35-2 Sakae-cho, Itabashi-ku, Tokyo, Japan \\ Email: ${ }^{*}$ shu-sawada@ruri.waseda.jp
}

Received 7 April 2014; revised 7 May 2014; accepted 17 May 2014

Copyright (C) 2014 by authors and Scientific Research Publishing Inc.

This work is licensed under the Creative Commons Attribution International License (CC BY). http://creativecommons.org/licenses/by/4.0/

cc) (†) Open Access

\begin{abstract}
MicroRNAs (miRNAs) have been reported as potentially being useful biomarkers for various diseases including cancer, diabetes mellitus, heart disease, neurological disease and age-related diseases. In the present study, we aimed to determine whether the expression levels of circulating miRNAs in serum were changed with aging or sex. Serum samples from seven elderly males (69.86 \pm 1.77 years old $)$ and females $(72.43 \pm 1.49$ years old $)$, and six young males $(26.17 \pm 0.83$ years old $)$ and females ( $23.17 \pm 1.52$ years old) were obtained from the subject's forearm at rest. The expression levels of circulating miR-146a and miR-20a in serum were determined by real-time TaqMan PCR. There were no differences in the expression levels of miR-146a between all groups. There was a significant interaction in this main effect where miR-20a levels were significantly lower in elderly male subjects when compared to young male subjects with no difference observed in young or elderly female subjects ( $p=0.004$ and $p=0.971$, respectively). These results suggest that not all the miRNAs in the circulation are influenced by the effect of aging, but only some miRNAs may be selectively changed by the effect of aging.
\end{abstract}

\section{Keywords}

miRNA, Serum, Aging, Sex Difference, Biomarker

${ }^{*}$ Corresponding author. 


\section{Introduction}

MicroRNAs (miRNAs) are small non-coding RNAs, which are approximately 22 nucleotides in length. MiRNAs interact with the 3' untranslated regions (UTRs) of target mRNAs via their 5' terminal sequences, thereby degrading and/or repressing translation of the mRNAs. Thus, it is hypothesized that miRNAs participate in the control of various biological phenomena [1] [2]. MiRNAs have been reported as potentially being useful biomarkers for various diseases including cancer, diabetes mellitus, heart disease, neurological disease and age-related diseases [3]-[12].

Previous studies have reported that some miRNA expression levels were changed with aging and sex. For example, out of 240 miRNAs, there were sex differences in the expression levels of $62 \%$ miRNAs in mouse brain tissue [13]. In humans, the expression level of miR-26a in liver tissue was higher in women than in men [14]. It has also been reported that miRNA expression varies with aging in several tissues and in blood. For example, among 599 miRNAs in the mouse heart, 31 miRNAs are downregulated and 34 miRNAs are upregulated with aging by more than 1.5 fold [15]. Quantitative analysis using real-time PCR revealed that miR-34a was increased in hearts of aged humans and mice [16]. In recent years, it has been suggested that senescent cells accumulate in aging individuals [17]. In senescent cells of mice and humans several miRNAs, including miR-34a and miR-146a, were increased [18]-[20]. Other studies have shown that miR-20a expression was associated with various senescence models [21]-[25]. The other studies have also shown that circulating levels of miR-21 [26], and miR-151a-3p, miR-181a-5p and miR-1248 were significantly decreased in elderly subjects when compared to young subjects [27].

One previous study has reported that circulating miR-146a was significantly increased after an acute bout of endurance exercise [28]. In contrast, we revealed that circulating miR-146a was significantly decreased three days after an acute bout of resistance exercise in humans [29], suggesting that circulating miRNAs are differentially influenced by different types of exercise. Other studies have reported that circulating miR-146a was decreased in patients with sepsis or systemic lupus erythematosus [30] [31], and increased in patients with hepatocellular carcinoma or liver cirrhosis [32], chronic hepatitis C virus infection [33], and congestive heart failure [19]. These findings may suggest that circulating miR-146a is possibly influenced by aging, which is closely related to inflammation, or estrogen, which has a strong anti-oxidative capacity and is reduced in postmenopausal women. However, it is unclear whether aging or sex differences are confounding factors of the miR-146a expression in the circulation.

On the other hand, it has been reported that miR-20a is related to cell senescence, as described above, but the influence of aging on miR-20a expression in blood has not been evaluated. In previous studies, miR-20a expression in blood was increased in patients with high risk the Cancer of the Prostate Risk Assessment scores [34], lymph node metastasis of early-stage cervical squamous cell carcinoma [35], hepatitis C virus infection [36], nasopharyngeal carcinoma [37], breast cancer [38] and gastric cancer [39], and decreased in patients with systemic lupus erythematosus [40] and chronic obstructive pulmonary disease [41]. However, it is unclear whether aging or sex differences are confounding factors of miR-20a expression in the circulation.

The purpose of this study was to evaluate whether the expression levels of circulating miR-146a and miR-20a in serum were changed with aging or sex differences. To verify this, we compared serum samples from young and elderly human males and females.

\section{Methods}

\subsection{Subjects and Ethical Approval}

Elderly subjects, aged 65 to 78 years old, were recruited from participants who qualified in the specific health checkup in Kusatsu-machi, Gunma prefecture, with the cooperation of Tokyo Metropolitan Institute of Gerontology. On the other hand, young subjects, aged 19 to 30 years old, were recruited from Waseda University. Data from seven elderly males (69.86 \pm 1.77 years old) and females (72.43 \pm 1.49 years old), and six young males (26.17 \pm 0.83 years old) and females (23.17 \pm 1.52 years old) were used in this study.

Written informed consent was obtained from all of the subjects. Ethical approval for this study was conformed to the standards of the Declaration of Helsinki, and the study protocol was approved by the Tokyo Metropolitan Institute of Gerontology Ethics Committee and the Waseda University Ethics Committee. 


\subsection{Blood Sampling and RNA Isolation}

Venous blood samples were obtained from the subject's forearm at rest. Serum samples were prepared by centrifugation of the whole blood at $1000 \times \mathrm{g}$ for $10 \mathrm{~min}$ following $30 \mathrm{~min}$ incubation at room temperature. Then, $400 \mu \mathrm{l}$ of the serum was mixed with five volumes of QIAzol reagent (Qiagen, Valencia, CA). To allow for normalization of sample-to-sample variation in RNA isolation, synthetic C. elegansmiRNAs, cel-miR-39, cel-miR54 and cel-miR-238 (synthetic RNA oligonucleotides synthesized by Fasmac, Odawara, Japan), were added (25 fmol of each oligonucleotide in a $5 \mu \mathrm{l}$ total volume) to each sample. These samples were stored at $-80^{\circ} \mathrm{C}$ until analysis.

Total RNA, including small RNAs, from $400 \mu \mathrm{l}$ of serum was isolated with miRNeasy Mini Kit (Qiagen, Valencia, CA) according to the manufacturer's instructions, with some modifications. Briefly, chloroform was added to the mixture of serum, QIAzol and synthetic C. elegans miRNAs, cel-miR-39, cel-miR-54 and cel-miR-238, in equal volume to the serum and vortexed well. After centrifuging for $15 \mathrm{~min}$ at $12,000 \times \mathrm{g}$ at $4^{\circ} \mathrm{C}$, the upper aqueous phase was transferred to a new collection tube, mixed with 1.5 volumes of $100 \%$ ethanol, and transferred to an RNeasy Mini spin column. After centrifuging for 1 min at $15,000 \times \mathrm{g}$ at $25^{\circ} \mathrm{C}, 700 \mu \mathrm{l}$ of Buffer RWT and $500 \mu \mathrm{l}$ of Buffer RPE were added to the RNeasy Mini spin column followed by centrifugation for 1 $\min$ at $15,000 \times \mathrm{g}$ at $25^{\circ} \mathrm{C}$ to wash the column. Finally, RNA was eluted with $50 \mu \mathrm{l}$ of elution buffer.

\section{3. miRNA Expression Analysis}

The TaqMan MicroRNA Reverse Transcription Kit and TaqMan MicroRNA assays (Applied Biosystems, Foster City, CA) were used for real-time PCR quantification of mature miR-146a and miR-20a expression levels [29]. The cel-miR-39 was used as an exogenous control for miRNA expression levels. The results of the real-time PCR were first presented as $\mathrm{Ct}$ values, and the $\Delta \Delta \mathrm{Ct}$ value was calculated for each miRNA using the $\mathrm{Ct}$ value of cel-miR-39 and the mean Ct value of miR-146a or miR-20a. Using the formula $2^{-\Delta \Delta \mathrm{Ct}}$, we calculated the fold-change in young females, elderly males and elderly females relative to young males.

\subsection{Statistical Analysis}

Quantitative miRNA expression data were analyzed using $\Delta \mathrm{Ct}$ values, normalized to cel-miR-39, for the target miRNA. Unpaired two-way ANOVA tests were used to test for differences between groups. Statistical significance was established at $p<0.05$. Data are presented as the means \pm standard error (SE).

\section{Result}

\subsection{Comparison of the Circulating miR-146a and miR-20a Levels}

Circulating miR-146a and miR-20a levels between male and female, and young subjects and elderly subjects were compared to determine age $\times$ sex interactions. There were no differences in the expression levels of miR-146a between elderly subjects and young subjects ( $p=0.151$; Figure $1(\mathrm{a}))$. The fold change for miR-146a in elderly subjects was 0.706 when compared to young subjects. We found that there were also no differences in the miR-146a levels between male and female groups $(p=0.757$; Figure $1(b))$. The fold change for miR-146a in females was 0.947 when compared to males.

On the other hand, miR-20a levels were significantly lower in elderly subjects when compared to young subjects $(p=0.032$; Figure 2(a)). The fold change for miR-20a in elderly subjects was 0.584 . However, there were no differences between male and female groups ( $p=0.922$; Figure 2(b)). The fold change for miR-20a in the female group was 1.066. We also observed a significant interaction in this main effect where miR-20a levels were significantly lower in elderly male subjects when compared to young male subjects with no difference observed in young or elderly female subjects ( $p=0.004$ and $p=0.971$, respectively; Figure 2(c)). When regarding the mean value of young male subjects as the standard value, the fold change in elderly male subjects was 0.346; it was 0.606 in young female subjects, and it was 0.598 in elderly female subjects (Figure 2(c)). The Ct values for the miRNAs were approximately 28 and 29 for miR-20a and miR-146a respectively.

\section{Discussion}

We initially hypothesized that the circulating miR-146a and miR-20a were influenced by age or sex differences. 


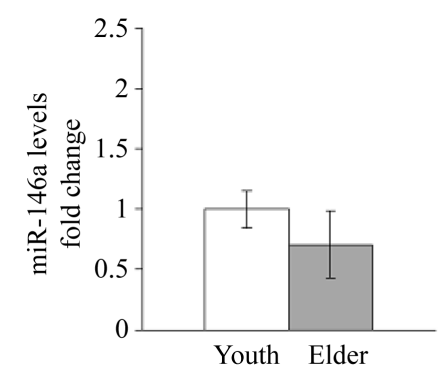

(a)

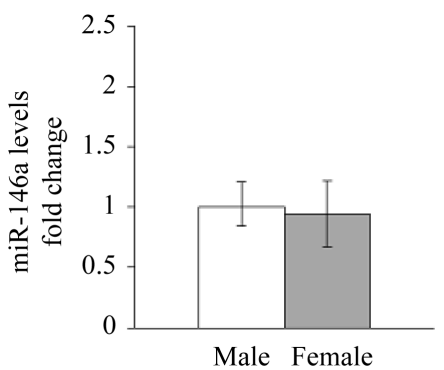

(b)

Figure 1. Comparison of circulating miR-146a levels between groups. The difference in circulating miR-146a levels compared between (a) young subjects and elderly subjects, and (b) male and female groups. Youth: young subjects; Elder: elderly subjects.

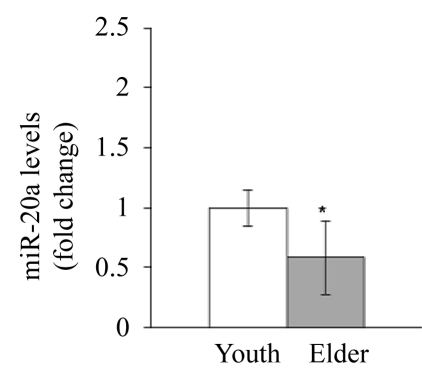

(a)

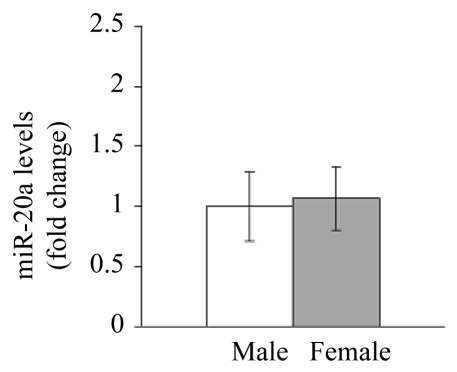

(b)

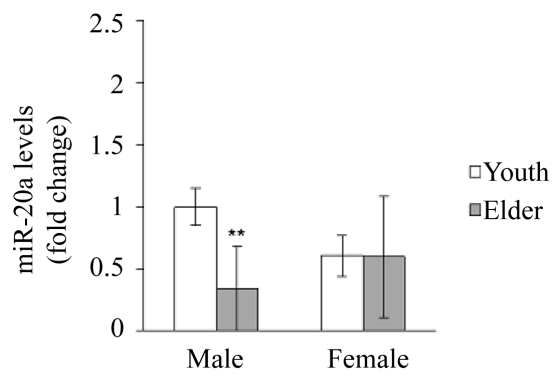

(c)

Figure 2. Comparison of circulating miR-20a levels between groups. (a) Circulating miR-20a levels compared between young subjects (n $=12$ ) and elderly subjects $(n=14) .{ }^{*} p<0.05$ when compared to young subjects. (b) Circulating miR-20a levels compared between male $(n=13)$ and female $(n=13)$ groups. (c) Circulating miR-20a levels compared among four groups; young male subjects $(n=6)$, elderly male subjects $(n=7)$, young female subjects $(n=6)$ and elderly female subjects $(\mathrm{n}=7) .{ }^{* *} p<0.01$ when compared to young male subjects. Youth: young subjects; Elder: elderly subjects.

Age and sex differences are important confounding factors when using medical data as biomarkers and also when analyzing miRNA data. At first, we focused on aging because it has been reported that miR-20a and miR146a were related to cell senescence. Cell senescence is a state of irreversible cell cycle arrest, and it has been described as the limit to the replicative lifespan of somatic cells in vitro [42]. Recent studies have shown that senescent cells triggered secrete various factors such as proinflammatory cytokines and chemokines [43]-[46]. This phenomenon is called senescence-associated secretory phenotype, and occurs in various tissues of old mice [47]. These findings suggest that cellular senescence is related to tissue, organ and body aging, and it might be possibly linked to the miRNA profile in blood. Secondly, we focused on sex differences. To date, there has been no report on difference in the expression of circulating miR-146a and miR-20a between males and females. 
When the quantitative miRNA expression data were analyzed, we normalized to cel-miR-39; it has been considered to be suitable for normalization and used well in previous studies because of not having similar sequence with known miRNA in human. Circulating miR-146a did not differ between groups, and according to this result, circulating miR-146a is not affected by aging or sex differences. On the other hand, circulating miR-20a levels were significantly lower in elderly subjects when compared to young subjects. We further demonstrated a significant interaction and revealed that miR-20a levels of elderly male subjects were significantly lower when compared to young male subjects and found no differences in young or elderly females. Though mechanism of the reduction in elderly male subjects has not been revealed, this indicates that aging and sex should be considered as a confounding factor when investigating the circulating levels of miR-20a. For example, in a previous study, circulating miR-20a was reported to be increased in patients with hepatitis $C$ virus infection [36], but the age and sex profiles were not matched between the control group and the patient group. On the one hand, another previous study reported that circulating miR-20a was decreased in the patients with chronic obstructive pulmonary disease [41], but the subjects' characteristics were not described. If miR-20a is to be used as a biomarker of these diseases, aging and sex must be considered as confounding factors. If the variation remains after the adjustment of these confounding factors, miR-20a may prove to be of great value as a biomarker.

In the present study, we revealed that the effect of aging on circulating miRNAs differs between miRNAs. This means that not all the miRNAs in the circulation are influenced by the effect of aging, but only some miRNAs may be selectively changed by the effect of aging. Our result suggests that we should examine the difference of circulating miRNAs in different population (age, sex, etc.) when we compare and analyze the expression levels of them among various subjects. Further studies are needed to evaluate the comprehensive changes of circulating miRNAs by the effect of aging and sex differences.

\section{Acknowledgements}

This study was supported in part by a Grant-in Aid for Scientific Research (A) from the Ministry of Education, Culture, Sports, Science, and Technology, Japan (23240097 to K.S.), and we would like to thank for the staff of Tokyo Metropolitan Institute of Gerontology and Waseda University.

\section{References}

[1] Kloosterman, W.P. and Plasterk, R.H. (2006) The Diverse Functions of MicroRNAs in Animal Development and Disease. Developmental Cell, 11, 441-450. http://dx.doi.org/10.1016/j.devcel.2006.09.009

[2] Bartel, D.P. (2004) MicroRNAs: Genomics, Biogenesis, Mechanism, and Function. Cell, 116, 281-297. http://dx.doi.org/10.1016/S0092-8674(04)00045-5

[3] De Smaele, E., Ferretti, E. and Gulino, A. (2010) MicroRNAs as Biomarkers for CNS Cancer and Other Disorders. Brain Research, 1338, 100-111. http://dx.doi.org/10.1016/j.brainres.2010.03.103

[4] Rao, P., Benito, E. and Fischer, A. (2013) MicroRNAs as Biomarkers for CNS Disease. Frontiers in Molecular Neuroscience, 6, 39.

[5] Li, C., Pei, F., Zhu, X., Duan, D.D. and Zeng, C. (2012) Circulating MicroRNAs as Novel and Sensitive Biomarkers of Acute Myocardial Infarction. Clinical Biochemistry, 45, 727-732. http://dx.doi.org/10.1016/j.clinbiochem.2012.04.013

[6] Wang, G.K., Zhu, J.Q., Zhang, J.T., Li, Q., Li, Y., He, J., Qin, Y.W. and Jing, Q. (2010) Circulating MicroRNA: A Novel Potential Biomarker for Early Diagnosis of Acute Myocardial Infarction in Humans. European Heart Journal, 31, 659-666. http://dx.doi.org/10.1093/eurheartj/ehq013

[7] Olivieri, F., Rippo, M.R., Procopio, A.D. and Fazioli, F. (2013) Circulating Inflamma-MiRs in Aging and Age-Related Diseases. Front Genetics, 4, 121. http://dx.doi.org/10.3389/fgene.2013.00121

[8] Kosaka, N., Iguchi, H. and Ochiya, T. (2010) Circulating MicroRNA in Body Fluid: A New Potential Biomarker for Cancer Diagnosis and Prognosis. Cancer Science, 101, 2087-2092. http://dx.doi.org/10.1111/j.1349-7006.2010.01650.x

[9] Madhavan, D., Cuk, K., Burwinkel, B. and Yang, R. (2013) Cancer Diagnosis and Prognosis Decoded by Blood-Based Circulating MicroRNA Signatures. Front Genetics, 4, 116. http://dx.doi.org/10.3389/fgene.2013.00116

[10] Zen, K. and Zhang, C.Y. (2012) Circulating MicroRNAs: A Novel Class of Biomarkers to Diagnose and Monitor Human Cancers. Medicinal Research Reviews, 32, 326-348. http://dx.doi.org/10.1002/med.20215

[11] Chen, X., Ba, Y., Ma, L., Cai, X., Yin, Y., Wang, K., Guo, J., Zhang, Y., Chen, J., Guo, X., Li, Q., Li, X., Wang, W., Zhang, Y., Wang, J., Jiang, X., Xiang, Y., Xu, C., Zheng, P., Zhang, J., Li, R., Zhang, H., Shang, X., Gong, T., Ning, 
G., Wang, J., Zen, K., Zhang, J. and Zhang, C.Y. (2008) Characterization of MicroRNAs in Serum: A Novel Class of Biomarkers for Diagnosis of Cancer and Other Diseases. Cell Research, 18, 997-1006. http://dx.doi.org/10.1038/cr.2008.282

[12] Vogel, B., Keller, A., Frese, K.S., Leidinger, P., Sedaghat-Hamedani, F., Kayvanpour, E., Kloos, W., Backe, C., Thanaraj, A., Brefort, T., Beier, M., Hardt, S., Meese, E., Katus, H.A. and Meder, B. (2013) Multivariate MiRNA Signatures as Biomarkers for Non-Ischaemic Systolic Heart Failure. European Heart Journal, 34, 2812-2822. http://dx.doi.org/10.1093/eurheartj/eht256

[13] Morgan, C.P. and Bale, T.L. (2012) Sex Differences in MicroRNA Regulation of Gene Expression: No Smoke, Just MiRs. Biology of Sex Differences, 3, 22. http://dx.doi.org/10.1186/2042-6410-3-22

[14] Ji, J., Shi, J., Budhu, A., Yu, Z., Forgues, M., Roessler, S., Ambs, S., Chen, Y., Meltzer, P.S., Croce, C.M., Qin, L.X., Man, K., Lo, C.M., Lee, J., Ng, I.O., Fan, J., Tang, Z.Y., Sun, H.C. and Wang, X.W. (2009) MicroRNA Expression, Survival, and Response to Interferon in Liver Cancer. New England Journal of Medicine, 361, 1437-1447. http://dx.doi.org/10.1056/NEJMoa0901282

[15] Zhang, X., Azhar, G. and Wei, J.Y. (2012) The Expression of MicroRNA and MicroRNA Clusters in the Aging Heart. PLoS One, 7, e34688. http://dx.doi.org/10.1371/journal.pone.0034688

[16] Boon, R.A., Iekushi, K., Lechner, S., Seeger, T., Fischer, A., Heydt, S., Kaluza, D., Tréguer, K., Carmona, G., Bonauer, A., Horrevoets, A.J., Didier, N., Girmatsion, Z., Biliczki, P., Ehrlich, J.R., Katus, H.A., Müller, O.J., Potente, M., Zeiher, A.M., Hermeking, H. and Dimmeler, S. (2013) MicroRNA-34a Regulates Cardiac Ageing and Function. Nature, 495, 107-110. http://dx.doi.org/10.1038/nature11919

[17] Kuilman, T., Michaloglou, C., Mooi, W.J. and Peeper, D.S. (2010) The Essence of Senescence. Genes \& Development, 24, 2463-2479. http://dx.doi.org/10.1101/gad.1971610

[18] Christoffersen, N.R., Shalgi, R., Frankel, L.B., Leucci, E., Lees, M., Klausen, M., Pilpel, Y., Nielsen, F.C., Oren, M., and Lund, A.H. (2010) p53-Independent Upregulation of MiR-34a during Oncogene-Induced Senescence Represses MYC. Cell Death and Differentiation, 17, 236-245. http://dx.doi.org/10.1038/cdd.2009.109

[19] Olivieri, F., Lazzarini, R., Recchioni, R., Marcheselli, F., Rippo, M.R., Di Nuzzo, S., Albertini, M.C., Graciotti, L., Babini, L., Mariotti, S., Spada, G., Abbatecola, A.M., Antonicelli, R., Franceschi, C. and Procopio, A.D. (2013) MiR146a as Marker of Senescence-Associated Pro-Inflammatory Status in Cells Involved in Vascular Remodelling. Age (Dordr), 35, 1157-1172. http://dx.doi.org/10.1007/s11357-012-9440-8

[20] Park, S., Kang, S., Min, K.H., Hwang, K.W. and Min, H. (2013) Age-Associated Changes in MicroRna Expression in Bone Marrow Derived Dendritic Cells. Immunological Investigations, 42, 179-190. http://dx.doi.org/10.3109/08820139.2012.717328

[21] Hackl, M., Brunner, S., Fortschegger, K., Schreiner, C., Micutkova, L., Mück, C., Laschober, G.T., Lepperdinger, G., Sampson, N., Berger, P., Herndler-Brandstetter, D., Wieser, M., Kühnel, H., Strasser, A., Rinnerthaler, M., Breitenbach, M., Mildner, M., Eckhart, L., Tschachler, E., Trost, A., Bauer, J.W., Papak, C., Trajanoski, Z., Scheideler, M., Grillari-Voglauer, R., Grubeck-Loebenstein, B., Jansen-Dürr, P. and Grillari, J. (2010) MiR-17, MiR-19b, MiR-20a, and MiR-106a Are Down-Regulated in Human Aging. Aging Cell, 9, 291-296. http://dx.doi.org/10.1111/j.1474-9726.2010.00549.x

[22] Greussing, R., Hackl, M., Charoentong, P., Pauck, A., Monteforte, R., Cavinato, M., Hofer, E., Scheideler ,M., Neuhaus, M., Micutkova, L., Mueck, C., Trajanoski, Z., Grillari, J. and Jansen-Dürr, P. (2013) Identification of MicroRNA-mRNA Functional Interactions in UVB-Induced Senescence of Human Diploid Fibroblasts.BMC Genomics, 14, 224. http://dx.doi.org/10.1186/1471-2164-14-224

[23] Hong, L., Lai, M., Chen, M., Xie, C., Liao, R., Kang, Y.J., Xiao, C., Hu, W.Y., Han, J. and Sun, P. (2010) The MiR17-92 Cluster of MicroRNAs Confers Tumorigenicity by Inhibiting Oncogene-Induced Senescence. Cancer Research, 70, 8547-8557. http://dx.doi.org/10.1158/0008-5472.can-10-1938

[24] Poliseno, L., Pitto, L., Simili, M., Mariani, L., Riccardi, L., Ciucci, A., Rizzo, M., Evangelista, M., Mercatanti, A., Pandolfi, P.P. and Rainaldi, G. (2008) The Proto-Oncogene LRF Is under Post-Transcriptional Control of MiR-20a: Implications for Senescence. PLOS ONE, 3, e2542. http://dx.doi.org/10.1371/journal.pone.0002542

[25] Wang, M., Cheng, Z., Tian, T., Chen, J., Dou, F., Guo, M. and Cong, Y.S. (2011) Differential Expression of Oncogenic MiRNAs in Proliferating and Senescent Human Fibroblasts. Molecular and Cellular Biochemistry, 352, 271-279. http://dx.doi.org/10.1007/s11010-011-0763-z

[26] Olivieri, F., Spazzafumo, L., Santini, G., Lazzarini, R., Albertini, M.C., Rippo, M.R., Galeazzi, R., Abbatecola, A.M., Marcheselli, F., Monti, D., Ostan, R., Cevenini, E., Antonicelli, R., Franceschi, C. and Procopio, A.D. (2012) AgeRelated Differences in the Expression of Circulating MicroRNAs: MiR-21 as a New Circulating Marker of Inflammaging. Mechanisms of Ageing and Development, 133, 675-685. http://dx.doi.org/10.1016/j.mad.2012.09.004

[27] Hooten, N., Fitzpatrick, M., Wood 3 ${ }^{\text {rd }}$, W.H., De, S., Ejiogu, N., Zhang, Y., Mattison, J.A., Becker, K.G., Zonderman, A.B. and Evans, M.K. (2013) Age-Related Changes in MicroRNA Levels in Serum. Aging (Albany NY), 5, 725-740. 
[28] Baggish, A.L., Hale, A., Weiner, R.B., Lewis, G.D., Systrom, D., Wang, F., Wang, T.J. and Chan, S.Y. (2011) Dynamic Regulation of Circulating MicroRNA during Acute Exhaustive Exercise and Sustained Aerobic Exercise Training. The Journal of Physiology, 589, 3983-3994. http://dx.doi.org/10.1113/jphysiol.2011.213363

[29] Sawada, S., Kon, M., Wada, S., Ushida, T., Suzuki, K. and Akimoto, T. (2013) Profiling of Circulating MicroRNAs after a Bout of Acute Resistance Exercise in Humans. PLoS ONE, 8, e70823. http://dx.doi.org/10.1371/journal.pone.0070823

[30] Wang, G., Tam, L.S., Li, E.K., Kwan, B.C., Chow, K.M., Luk, C.C., Li, P.K. and Szeto, C.C. (2010) Serum and Urinary Cell-Free MiR-146a and MiR-155 in Patients with Systemic Lupus Erythematosus. The Journal of Rheumatology, 37, 2516-2522. http://dx.doi.org/10.3899/jrheum.100308

[31] Wang, J.F., Yu, M.L., Yu, G., Bian, J.J., Deng, X.M., Wan, X.J. and Zhu, K.M. (2010) Serum MiR-146a and MiR-223 as Potential New Biomarkers for Sepsis. Biochemical and Biophysical Research Communications, 394, 184-188. http://dx.doi.org/10.1016/j.bbrc.2010.02.145

[32] Gui, J., Tian, Y., Wen, X., Zhang, W., Zhang, P., Gao, J., Run, W., Tian, L., Jia, X. and Gao, Y. (2011) Serum MicroRNA Characterization Identifies MiR-885-5p as a Potential Marker for Detecting Liver Pathologies. Clinical Science (London), 120, 183-193. http://dx.doi.org/10.1042/CS20100297

[33] Bala, S., Tilahun, Y., Taha, O., Alao, H., Kodys, K., Catalano, D. and Szabo, G. (2012) Increased MicroRNA-155 Expression in the Serum and Peripheral Monocytes in Chronic HCV Infection. Journal of Translational Medicine, 10, 151. http://dx.doi.org/10.1186/1479-5876-10-151

[34] Shen, J., Hruby, G.W., McKiernan, J.M., Gurvich, I., Lipsky, M.J., Benson, M.C. and Santella, R.M. (2012) Dysregulation of Circulating MicroRNAs and Prediction of Aggressive Prostate Cancer. The Prostate, 72, 1469-1477. http://dx.doi.org/10.1002/pros.22499

[35] Chen, J., Yao, D., Li, Y., Chen, H., He, C., Ding, N., Lu, Y., Ou, T., Zhao, S., Li, L. and Long, F. (2013) Serum MicroRNA Expression Levels Can Predict Lymph Node Metastasis in Patients with Early-Stage Cervical Squamous Cell Carcinoma. International Journal of Molecular Medicine, 32, 557-567.

[36] Shrivastava, S., Petrone, J., Steele, R., Lauer, G.M., Di Bisceglie, A.M. and Ray, R.B. (2013) Up-Regulation of Circulating MiR-20a Is Correlated with Hepatitis C Virus-Mediated Liver Disease Progression. Hepatology, 58, 863-871. http://dx.doi.org/10.1002/hep.26296

[37] Zeng, X., Xiang, J., Wu, M., Xiong, W., Tang, H., Deng, M., Li, X., Liao, Q., Su, B., Luo, Z., Zhou, Y., Zhou, M., Zeng, Z., Li, X., Shen, S., Shuai, C., Li, G., Fang, J. and Peng, S. (2012) Circulating MiR-17, MiR-20a, MiR-29c, and MiR-223 Combined as Non-Invasive Biomarkers in Nasopharyngeal Carcinoma. PLoS ONE, 7, e46367. http://dx.doi.org/10.1371/journal.pone.0046367

[38] Schwarzenbach, H., Milde-Langosch, K., Steinbach, B., Müller, V. and Pantel, K. (2012) Diagnostic Potential of PTEN-Targeting MiR-214 in the Blood of Breast Cancer Patients. Breast Cancer Research and Treatment, 134, 933941. http://dx.doi.org/10.1007/s10549-012-1988-6

[39] Liu, R., Zhang, C., Hu, Z., Li, G., Wang, C., Yang, C., Huang, D., Chen, X., Zhang, H., Zhuang, R., Deng, T., Liu, H., Yin, J., Wang, S., Zen, K., Ba, Y. and Zhang, C.Y. (2011) A Five-MicroRNA Signature Identified from Genome-Wide Serum MicroRna Expression Profiling Serves as a Fingerprint for Gastric Cancer Diagnosis. European Journal of Cancer, 47, 784-791. http://dx.doi.org/10.1016/j.ejca.2010.10.025

[40] Carlsen, A.L., Schetter, A.J., Nielsen, C.T., Lood, C., Knudsen, S., Voss, A., Harris, C.C., Hellmark, T., Segelmark, M., Jacobsen, S., Bengtsson, A.A. and Heegaard, N.H. (2013) Circulating MicroRNA Expression Profiles Associated with Systemic Lupus Erythematosus. Arthritis \& Rheumatism, 65, 1324-1334. http://dx.doi.org/10.1002/art.37890

[41] Akbas, F., Coskunpinar, E., Aynaci, E., Oltulu, Y.M. and Yildiz, P. (2012) Analysis of Serum Micro-RNAs as Potential Biomarker in Chronic Obstructive Pulmonary Disease. Experimental Lung Research, 38, 286-294. http://dx.doi.org/10.3109/01902148.2012.689088

[42] Hayflick, L. and Moorhead, P.S. (1961) The Serial Cultivation of Human Diploid Cell Strains. Experimental Cell Research, 25, 585-621. http://dx.doi.org/10.1016/0014-4827(61)90192-6

[43] Coppe, J.P., Patil, C.K., Rodier, F., Sun, Y., Munoz, D.P., Goldstein, J., Nelson, P.S., Desprez, P.Y. and Campisi, J. (2008) Senescence-Associated Secretory Phenotypes Reveal Cell-Nonautonomous Functions of Oncogenic RAS and the p53 Tumor Suppressor. PLoS Biology, 6, 2853-2868. http://dx.doi.org/10.1016/0014-4827(61)90192-6

[44] Kuilman, T., Michaloglou, C., Vredeveld, L.C., Douma, S., van Doorn, R., Desmet, C.J., Aarden, L.A., Mooi, W.J. and Peeper, D.S. (2008) Oncogene-Induced Senescence Relayed by an Interleukin-Dependent Inflammatory Network. Cell, 133, 1019-1031. http://dx.doi.org/10.1016/j.cell.2008.03.039

[45] Coppé, J.P., Patil, C.K., Rodier, F., Krtolica, A., Beausejour, C.M., Parrinello, S., Hodgson, J.G., Chin, K., Desprez, P.Y. and Campisi, J. (2010) A Human-Like Senescence-Associated Secretory Phenotype Is Conserved in Mouse Cells Dependent on Physiological Oxygen. PLoS ONE, 5, e9188. http://dx.doi.org/10.1371/journal.pone.0009188 
[46] Acosta, J.C., O’Loghlen, A., Banito, A., Guijarro, M.V., Augert, A., Raguz, S., Fumagalli, M., Da Costa, M., Brown, C., Popov, N., Takatsu, Y., Melamed, J., di Fagagna, F.D., Bernard, D., Hernando, E. and Gil, J. (2008) Chemokine Signaling via the CXCR2 Receptor Reinforces Senescence. Cell, 133, 1006-1018. http://dx.doi.org/10.1016/j.cell.2008.03.038

[47] Takahashi, A., Imai, Y., Yamakoshi, K., Kuninaka, S., Ohtani, N., Yoshimoto, S., Hori, S., Tachibana, M., Anderton, E., Takeuchi, T., Shinkai, Y., Peters, G., Saya, H. and Hara, E. (2012) DNA Damage Signaling Triggers Degradation of Histone Methyltransferases through APC/C ${ }^{\text {Cdh1 }}$ in Senescent Cells. Molecular Cell, 45, 123-131. http://dx.doi.org/10.1016/j.molcel.2011.10.018 